\title{
Improvement of Stability and Cell Adhesion Properties of Polyelectrolyte Multilayer Films by Chemical Cross-Linking
}

\author{
Ludovic Richert, ${ }^{\dagger}$ Fouzia Boulmedais, ${ }^{\dagger}$ Philippe Lavalle, ${ }^{\dagger}$ Jerome Mutterer, ${ }^{\ddagger}$ \\ Emmanuelle Ferreux, ${ }^{\dagger}$ Gero Decher,,${ }^{\circledR}$ Pierre Schaaf,,,$\|$ Jean-Claude Voegel, ${ }^{\dagger}$ and \\ Catherine Picart ${ }^{*},, \|$
}

\begin{abstract}
Institut National de la Santé et de la Recherche Médicale, Unite 595, Faculté de Chirurgie Dentaire, Université Louis Pasteur, 11 rue Humann, 67085 Strasbourg Cedex, France, Ecole Europeenne de Chimie, Polymères et Matériaux de Strasbourg, 25 rue Becquerel, 67087 Strasbourg Cedex 2. France, Institut de Biologie Moleculaire des Plantes, 12 rue du General Zimmer, 67084 Strasbourg Cedex, France, and Institut Charles Sadron, Centre National de la Recherche Scientifique, Université Louis Pasteur, 6 rue Boussingault, 67083 Strasbourg Cedex, France
\end{abstract}

Received July 8, 2003; Revised Manuscript Received October 8, 2003

\begin{abstract}
Poly(L-lysine)/hyaluronan (PLL/HA) films were chemically cross-linked with a water soluble carbodiimide (EDC) in combination with a $\mathrm{N}$-hydroxysulfo-succinimide (NHS) to induce amide formation. Fourier transform infrared spectroscopy confirms the conversion of carboxylate and ammonium groups into amide bonds. Quartz crystal microbalance-dissipation reveals that the cross linking reaction is accompanied by a change in the viscoelastic properties of the films leading to more rigid films. After the cross-linking reaction, both positively and negatively ending films exhibit a negative zeta potential. It is shown by fluorescence recovery after photobleaching measured by confocal laser scanning microscopy that cross-linking dramatically reduces the diffusion of the PLL chains in the network. Cross linking also renders the films highly resistant to hyaluronidase, an enzyme that naturally degrades hyaluronan. Finally, the adhesion of chondrosarcoma cells on the films terminating either with PLL or HA is also investigated. Whereas the non cross-linked films are highly resistant to cell adhesion, the cells adhere and spread well on the cross-linked films.
\end{abstract}

\section{Introduction}

Surface modifications of materials is of primary importance for biomedical applications. ${ }^{1-3}$ Among the different techniques used to modify surfaces, the deposition of polyelectrolyte multilayers (PEM) has emerged as a very easy handling and versatile tool. ${ }^{4-7}$ Based on the alternate adsorption of polycations and polyanions, this technique allows films to be built-up with tunable properties: by adjusting several parameters such as the chemical nature of the polyelectrolytes, $\mathrm{pH}$ and ionic strength, immersion and rinsing times, post-treatment of the film, it is possible to obtain an almost infinite variety of architectures. ${ }^{8-10}$ Of special importance for biomedical applications is the control of the chemical composition of the surface which can affect biological activity. Films made from polypeptides, i.e., poly(L-lysine), natural polyelectrolytes, or biopolymers (e.g., hyaluronan, alginate, chitosan, and collagen), allow, for example, biomimetic architectures to be created. ${ }^{11-14}$ Ap-

* To whom correspondence should be addressed. Address: INSERM U595, Faculté de Médecine, Bât 3, 11 rue Humann, 67085 Strasbourg cedex, France. Phone: 33-3-90-24-32-58. Fax: 33-3-90-24-33-79. E-mail: Catherine.Picart@medecine.u-strasbg.fr.

† Institut National de la Santé et de la Recherche Médicale, Université Louis Pasteur.

$\$$ Institut de Biologie Moléculaire des Plantes.

$\S$ Institut Charles Sadron, Université Louis Pasteur.

"Ecole Européenne de Chimie, Polymères et Matériaux de Strasbourg. plications include also the fabrication of nonadhesive barriers for vascular grafts, ${ }^{11}$ the fabrication of films with pro- or anti-coagulant properties, ${ }^{12}$ or the preparation of hollow capsules for drug release. ${ }^{13}$ Bioactivity of the films can be achieved by their functionalization by inserting peptides coupled to polyelectrolytes ${ }^{15}$ or through the embedding of proteins. ${ }^{16}$ For biomaterial applications, biocompatibility is a major requirement: the material must be nontoxic to any living cell. Another requirement is that the material possesses chemical and physical properties that promote specific cell substrate interactions, either cell adhesion or nonadhesion depending on the final application. Along this line, it was shown that primary cells can be grown on poly(styrenesulfonate)/poly(allylamine hydrochloride) films ${ }^{17}$ and on poly(L-lysine)/poly(L-glutamic acid) films for several days while maintaining their phenotype. ${ }^{18}$ Recently, Mendelsohn et al. ${ }^{19}$ showed that poly(acrylic acid)/poly(allylamine hydrochloride) multilayers can be either nonadhesive or adhesive depending on the $\mathrm{pH}$ of preparation of the films. These authors suggested that the nonadhesive character of the films with respect to cells is related to their high swelling capacities and is independent of their adhesive or nonadhesive character with respect to proteins from serum.

For various applications, the preservation of the structural integrity of the film is crucial. ${ }^{20}$ Polyelectrolyte multilayers based on biopolymers or polypeptides are hydrogels and must be considered as "soft" and sensitive materials. For example, 
exposure to solvents, $\mathrm{pH}$, and ionic strength jumps can affect their structural integrity, 9,21 and cross-linking constitutes a possible way to stabilize them. Until now, only few crosslinkable PEM systems have been reported. The approaches generally rely on the cross-linking through condensation reaction of complementary groups located on adjacent layer. The different strategies make use of bifunctional aldehydes such as glutaraldehyde, ${ }^{22,23}$ incorporation of diazoresins that are subsequently exposed to UV light, ${ }^{24}$ and more recently, cross-linking of hybrid clay/polyelectrolyte layers using a photocross-linkable polyelectrolyte ${ }^{25}$ and of proteins multilayers ${ }^{26}$ by carbodiimide chemistry. Heating the films at high temperature $\left(130{ }^{\circ} \mathrm{C}\right)$ for several hours was also explored..$^{27-29}$ Depending on the types of polyelectrolytes used, heating could produce amide ${ }^{27}$ or imide bonds. ${ }^{29}$ Cross-linking not only enhances the stability of the films but it allows also to change their permeability, conductivity, ${ }^{28,30}$ and eventually also their viscoelastic properties. All of these cross-linking methods also present however drawbacks. Introducing linker molecules such as glutaraldehyde may, for example, not only modify the film structure in a noncontrolled manner but also may change its biocompatibility. On the other hand, heating is not always possible depending upon the nature of the substrate.

As an alternative method, we investigate in this article the cross-linking of poly(L-lysine)/hyaluronan multilayers with a water soluble carbodiimide, 1-ethyl-3-(3-dimethylaminopropyl) carbodiimide (EDC), which is commonly used for the covalent attachment of proteins on surfaces. ${ }^{31}$ EDC catalyzes the formation of amide bonds between carboxylic groups of HA and amine groups of PLL. The cross linking reaction will be favored by the presence of $N$-hydroxysulfo succinimide (NHS). ${ }^{32}$ EDC alone has already been used for the cross-linking of hyaluronan solutions ${ }^{33}$ and hyaluronan/ collagen sponges. ${ }^{34}$ In contrast to conventional agents, such as glutaraldehyde or polyepoxides, carbodiimides do not remain as a part of that linkages but simply change to water soluble urea derivatives that have very low cytotoxicity. ${ }^{33,35}$ The cross-linking reaction will be followed by Fourier transformed infrared spectroscopy (FTIR). The quartz crystal microbalance-dissipation (QCM-D) technique will furnish information on the evolution of the viscoelastic properties of the film. The film will also be characterized by zeta potential measurements and confocal laser scanning microscopy (CLSM). Finally, cellular adhesion properties onto the native and on cross-linked (PLL/HA) films will be investigated. These later experiments are motivated by previous results obtained on thick polyacrylamide gels whose elasticity was changed by adjusting the percentage of bis-acrylamide. ${ }^{36,37}$ These authors found evidence that cell adhesion strongly depended on the substrate viscoelastic properties and was increased as substrate compliance was decreased.

\section{Materials and Methods}

Polyelectrolyte Solutions. The preparation of solutions of poly(L-lysine) (PLL, $30 \mathrm{kDa}$, Sigma, France), hyaluronan (HA, $400 \mathrm{kDa}$, Bioiberica, Spain), and the buildup of (PLL/
HA) $)_{i}$ films was previously described. ${ }^{14} \mathrm{PLL}$ and HA were dissolved at $1 \mathrm{mg} / \mathrm{mL}$ in $0.15 \mathrm{M} \mathrm{NaCl}$ at $\mathrm{pH}$ 6-6.5. During the film construction, all the rinsing steps were performed with an aqueous solution containing $0.15 \mathrm{M} \mathrm{NaCl}$ at $\mathrm{pH}$ 6-6.5. Fluorescein isothiocyanate labeled PLL (PLL-FITC), 1-ethyl-3-(3-dimethylaminopropyl) carbodiimide (EDC), $\mathrm{N}$ hydroxysulfo-succinimide (sulfo-NHS), and hyaluronidase (Type I) were purchased from Sigma-Aldrich and used without any purification.

Chemical Cross-Linking of the Films by EDC/NHS. Cross-linking was performed on films deposited either on the $\mathrm{ZnSe}$ coated crystal (for FTIR experiments), on the $\mathrm{SiO}_{2}$ crystal (for quartz crystal microbalance experiments), or on the $12 \mathrm{~mm}$ glass slides introduced in 24 wells culture plates. EDC solution alone $(200 \mathrm{mM})$ or a EDC/sulfo-NHS mixture (EDC at $400 \mathrm{mM}$ and NHS at $100 \mathrm{mM}$ were mixed $\mathrm{v} / \mathrm{v}$ ) were freshly prepared in a $0.15 \mathrm{M} \mathrm{NaCl}$ solution at $\mathrm{pH} 5.5$. The coupling chemistry is based on the reaction of activated carboxylic sites with primary amine groups. ${ }^{38}$ The film coated substrate was put in contact with the mixed EDC/NHS solution for $12 \mathrm{~h}$ (for clarity, the simplified notation EDC/ NHS will be used instead of the complete writing EDC/sulfoNHS). Rinsing was performed three times with a $0.15 \mathrm{M}$ $\mathrm{NaCl}$ solution for $1 \mathrm{~h}$. For the FTIR experiments, a similar protocol was used except that the EDC and NHS were dissolved in a deuterated $0.15 \mathrm{M} \mathrm{NaCl}$ solution.

Fourier Transform Infrared Spectroscopy in Attenuated Total Reflection. The crosslinking of (PLL/HA) $)_{8}$ films deposited on a ZnSe crystal was investigated by in situ Fourier transform infrared (FTIR) spectroscopy in attenuated total reflection (ATR) mode with an Equinox 55 spectrophotometer (Bruker, Wissembourg, France). All the experimental details have been given previously. ${ }^{39}$ The experiments were performed in a deuterated $0.15 \mathrm{M} \mathrm{NaCl}$ solution at $\mathrm{pH}$ $\approx 6 . \mathrm{D}_{2} \mathrm{O}$ is used as the solvent instead of water because the amide I bands of both PLL and HA are affected by the strong water band absorption around $1643 \mathrm{~cm}^{-1}(\mathrm{O}-\mathrm{H}$ bending), whereas the corresponding vibration in $\mathrm{D}_{2} \mathrm{O}$ is found around $1209 \mathrm{~cm}^{-1}$. During the buildup, the film was continuously in contact with the $0.15 \mathrm{M} \mathrm{NaCl}$ solution and was never dried. After each polyelectrolyte deposition, rinsing step, and the final contact with the EDC/NHS solution, single-channel spectra from 512 interferograms were recorded between 400 and $4000 \mathrm{~cm}^{-1}$ with a $2 \mathrm{~cm}^{-1}$ resolution, using Blackman-Harris three-term apodization and the standard Bruker OPUS/IR software (version 3.0.4). Analysis of the raw spectrum was performed at the end of the film buildup by taking the (PLL/HA $)_{8}$ film spectrum and subtracting the contribution of the $\mathrm{ZnSe}$ crystal. During the contact of the (PLL/HA $)_{8}$ film with the EDC/NHS solution, single-channel spectra from 512 interferograms were recorded every $20 \mathrm{~min}$. To follow the kinetics of the crosslinking reaction, difference spectra were calculated for a given time period by considering the actual raw spectra and subtracting to its value the contribution of the (PLL/HA) 8 film (before contact with the EDC/NHS solution).

Quartz Crystal Microbalance. The (PLL/HA) film buildup and the cross-linking process were followed in situ optical waveguide lightmode spectroscopy $y^{40,41}$ and by quartz 
crystal microbalance-dissipation (QCM-D, Q-sense AB, Götenborg, Sweden) ${ }^{42,43}$ These techniques have already been described and used for the characterization of (PLL/HA) films. ${ }^{14,44}$ The quartz crystal is excited at its fundamental frequency (about $5 \mathrm{MHz}$ ) as well as at the third, fifth, and seventh overtones (denoted by $v=3, v=5, v=7$ and corresponding respectively to 15,25 , and $35 \mathrm{MHz}$ ). Changes in the resonance frequencies $\Delta f$ and in the relaxation of the vibration once the excitation is stopped are measured at the four frequencies. The relaxation gives access to the dissipation $D$ of the vibrational energy stored in the resonator. A decrease in $\Delta f / v$ is usually associated, in a first approximation, to an increase of the mass coupled to the quartz and a decrease of $D$ at constant mass is usually associated to a stiffer (less elastic) film. Both $\Delta f / v$ and $D$ at the four resonance frequencies give thus information on the viscoelastic properties of the film. After the buildup of a (PLL/ $\mathrm{HA})_{7}$ film or a (PLL/HA $)_{7}-\mathrm{PLL}$ film, $2 \mathrm{~mL}$ of the EDC/ NHS solution were injected in the measuring cell, left at rest for $12 \mathrm{~h}$ and then rinsed. The QCM and OWLS signals were followed during the whole period.

Zeta Potential Measurements. Measurements of the zeta potential of the layers adsorbed on a capillary were carried out on a homemade streaming potential measurement apparatus developed by Zembala and Déjardin. ${ }^{45}$ The apparatus has been previously described. ${ }^{14,46}$ By measuring the pressure and the potential differences on both sides of a $530 \mu \mathrm{m}$ radius capillary made of fused silica via two flasks containing four electrodes, one gets access, through the Smoluchowski relation, to the zeta potential of the capillary. Details about the procedure are given in Picart et al. ${ }^{14}$ Polyelectrolytes were adsorbed in the $0.15 \mathrm{M} \mathrm{NaCl}$ solution, and measurements were performed after the rinsing of each layer at a ionic strength of $5 \times 10^{-4} \mathrm{M}(\mathrm{pH}=6)$. For cross-linking, $8 \mathrm{~mL}$ of the EDC/NHS in $0.15 \mathrm{M} \mathrm{NaCl}$ were injected in the capillary, left at rest for $12 \mathrm{~h}$ and rinsed before measurement.

Automatic Buildup of the Polyelectrolyte Multilayered Films for CLSM and Cell Culture Experiments. For CLSM and cell culture experiments, the multilayers were prepared with a dipping machine (Dipping Robot DR3, Kierstein GmbH, Germany) on $12 \mathrm{~mm}$ glass slides (VWR Scientific, France) preliminarily cleaned with 10 mM SDS and $0.1 \mathrm{~N} \mathrm{HCl}$ and extensively rinsed. The glass slides were introduced vertically in a homemade holder which was dipped into a polyelectrolyte solution for $10 \mathrm{~min}$ and was subsequently rinsed in three different beakers containing the $0.15 \mathrm{M} \mathrm{NaCl}$ solution. The slides were dipped four times (15 s each) in the first beaker and once for five minutes in the two other beakers. The slides were then dipped into the oppositely charged polyelectrolyte solution followed by the same rinsing procedure. Rinsing beakers were changed every three layers. Slides were then stored at $4{ }^{\circ} \mathrm{C}$ until use in 24 wells culture plates.

Confocal Laser Scanning Microscopy (CLSM). PLLFITC was used to image the dye labeled film in the green channel. The configuration of the microscope and the parameters used for the CLSM observations on a Zeiss LSM510 microscope have been given elsewhere. ${ }^{44}$ The 12 $\mathrm{mm}$ glass slides were introduced in a homemade chamber and observed by imaging series of consecutive overlapping optical sections. The thickness of the film was determined by the measurement of the green band (corresponding to the PLL-FITC) in computed orthogonal vertical sections through the imaged volumes. For the fluorescence recovery after photobleaching experiments (FRAP), a circular zone was bleached in the center of the image by iterative illumination at $488 \mathrm{~nm}$. Images were taken before, right after, and 30 min after the bleach process.

Cell Culture. HCS-2/8 human chondrosarcoma cells derived from chondrocyte-like cell line ${ }^{47}$ were routinely grown in Gibco BRL's minimum essential medium with Eagle's salts (MEM, Life Technologies), 10\% fetal calf serum (FCS, Life Technologies), $50 \mathrm{U} / \mathrm{mL}$ penicillin, and $50 \mathrm{U} / \mathrm{mL}$ streptomycin (Bio-Whittaker) in a $5 \% \mathrm{CO}_{2}$ and $95 \%$ air atmosphere at $37^{\circ} \mathrm{C}$. A flask of cells was brought into suspension after incubating for $2.5 \mathrm{~min}$ in $0.5 \%$ trypsin (Bio-Whittaker). Following trypsinization, cells were washed twice by centrifugation to a pellet at $500 \mathrm{~g}$ for $5 \mathrm{~min}$ and resuspended in $10 \mathrm{~mL}$ of fresh medium containing $10 \%$ FCS with serum. The (PLL/HA) $)_{12}$ or (PLL/HA) ${ }_{12}-$ PLL films, either native or cross-linked, with EDC/NHS, were deposited on $12 \mathrm{~mm}$ glass slide that were put in a 24 wells culture plate. These twelve bilayers thick films were chosen such as to have a uniform film on the glass substrate as was previously checked by AFM. ${ }^{14} 3 \times 10^{4}$ cells were deposited in each well.

\section{Results and Discussion}

Comparison of the Action of EDC Alone and EDC Combined to Sulfo-NHS. In the literature, there are many works aimed at cross-linking HA for biomedical purposes. In fact, the introduction of functional groups on HA is a subject of great interest. ${ }^{48}$ An early report claimed that carbodiimide-catalyzed reaction of HA with glycine methyl ester, a mononfunctional amine, led to the formation of an amide linkage. ${ }^{49}$ More recently, Tomihata et al. ${ }^{33}$ showed that EDC mediates an ester bond formation between the hydroxyl and carboxyl groups of HA. These authors also observed that adding L-lysine methyl ester in the HA solution leads to the formation of an amide bond. Indeed, in vivo degradation of the cross-linked films in the medium containing lysine ester underwent slower degradation indicating a more stable linkage for the amide bond than for the ester bond. Park et al. also used only EDC for cross-linking their HA gels. ${ }^{34}$ For HA solutions only (not containing the methyl ester), the EDC reaction could only be carried out at a very high polysaccharide concentration and at very low water concentration. Beside results obtained on HA molecules, EDC was also found to modify the side-groups on proteins to make them reactive with other side groups. This was the case for collagen/HA sponges, for which amide bonds could be formed between the amine groups of collagen and the carboxyl groups of HA, and ester linkages between the carboxyl groups of HA and the hydroxyl groups of HA or collagen. ${ }^{34}$

However, other studies showed that amide linkages could not be formed for HA alone in the presence of only EDC. ${ }^{50,51}$ 
Scheme 1. Coupling Scheme between PLL and HA in the Presence of Only EDC ${ }^{a}$

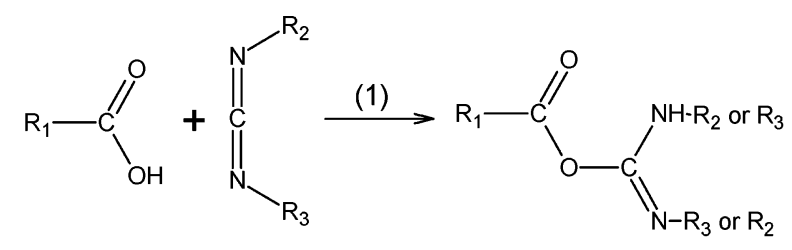

(HA) (EDC)
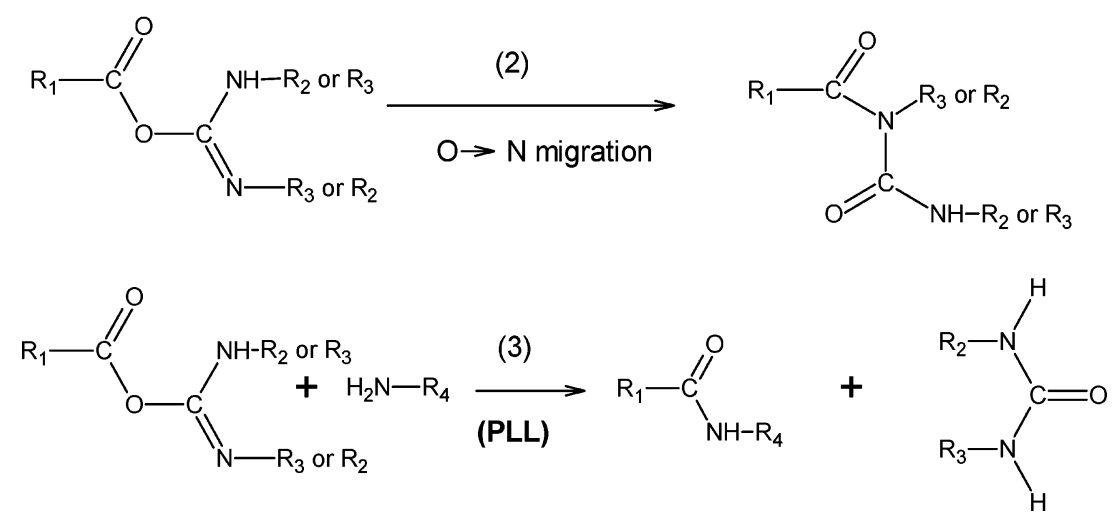

${ }^{a}$ EDC reacts with a carboxylic group and activates it to give a $\mathrm{O}$-acylisourea intermediate (1). The $\mathrm{O}$-acylisourea may rearrange to a stable $\mathrm{N}$-acylurea by way of a cyclic electronic displacement (2). ${ }^{52,51}$ It may also react with an amine group (such as PLL) to form an amide bond (3).

In fact, EDC reacts with available carboxyl groups to form active $O$-acylisourea intermediates (Scheme 1, step 1). However, under mild acidic conditions and in the absence of nucleophiles, the $O$-acylsourea intermediates can also rearrange by a cyclic electronic displacement to a stable $\mathrm{N}$-acylurea (Scheme 1, step 2). ${ }^{51-54}$ This irreversible reaction is reported to hinder the formation of the desired amide linkage. ${ }^{49,54}$ Eventually, the $O$-acylsourea can react directly with the amine of PLL (Scheme 1, step 3).

To enhance the efficiency of coupling between HA and primary amines, it is possible to add sulfo-NHS to the reaction, an esterification reagent that is known to enhance the formation of amide bonds. ${ }^{38}$ In the presence of both carboxylic and amine groups, the coupling chemistry is based on the following reaction scheme (Scheme 2). ${ }^{38}$ Beside the reactions already described in Scheme 1 (step 2 and 3), the $O$-acylisourea intermediates react with sulfo-NHS to give the NHS-ester intermediates (Scheme 2, step 2). For kinetic reasons, this later reaction is strongly preferred. This reaction being faster than $\mathrm{O} \rightarrow \mathrm{N}$ migration of $O$-acylisourea, this NHS-ester activated site reacts with primary amine sites to form an amide derivative (Scheme 2, step 3). For these reasons, precisely, the EDC/NHS reaction is more efficient than the EDC reaction alone. Failure to react with an amine results in hydrolysis of the intermediate, regeneration of the carboxyls and the release of sulfo-NHS (Scheme 2, step 4). Moreover, it was recently shown that, in the presence of EDC/NHS, HA could react with different amines to form amide linkages. ${ }^{53}$ More generally, this technique was successfully used for coupling amine and carboxyl groups. ${ }^{55}$

Therefore, we chose to use a mixture of EDC/NHS (200 $\mathrm{mM} / 50 \mathrm{mM}$ ). Some control experiments have been done using only EDC (200 mM). However, as will be shown below and as anticipated, EDC alone was not sufficient to fully cross-link PLL to HA and to affect the cellular adhesion properties of the film.

Cross-Linking Reaction followed by FTIR. The crosslinking between ammonium groups of PLL and carboxylate groups of HA in the presence of EDC/NHS was first followed by FTIR-ATR. Figure 1A shows a typical spectrum of a $(\mathrm{PLL} / \mathrm{HA})_{8}$ film deposited on a $\mathrm{ZnSe}$ crystal before contact with the EDC/NHS solution. The peaks of HA attributed to $-\mathrm{COO}^{-}$asymmetric and symmetric stretches (1606, $1412 \mathrm{~cm}^{-1}$ respectively) can be clearly identified. ${ }^{56}$ The amide I and amide II bands for HA appear respectively at $1650-1675$ and $1530-1565 \mathrm{~cm}^{-1}$ (in water). ${ }^{56}$ For PLL in $\mathrm{D}_{2} \mathrm{O}$, the amide $\mathrm{I}$ is located at $1600-1680 \mathrm{~cm}^{-1}$ and the amide II band at $1450 \mathrm{~cm}^{-1}$.57,58

It has to be noticed that all of the frequencies appearing in our spectra correspond closely to those found by FTIR for hyaluronan in water ${ }^{56,59}$ although our experiments were performed in $\mathrm{D}_{2} \mathrm{O}$. This indicates that the HA constituting the multilayer is still highly hydrated. The spectrum evolves as soon as the film is brought in contact with the EDC/NHS solution. The kinetics of the cross-linking reaction emerges more clearly by following the difference between the actual spectrum and the spectrum recorded before contact with EDC/NHS. The evolutions of these difference spectra as a function of the contact time between the film and the EDC/ NHS solution are shown in Figure 1B. As the contact time increases, the intensity of the peaks attributed to the carboxylic groups $\left(1606,1412 \mathrm{~cm}^{-1}\right)$ decreases and correlatively the intensity of the amide bands increases (1620$\left.1680 \mathrm{~cm}^{-1}\right)$. This is a strong indication for the formation of amide bonds between PLL and HA at the expense of carboxylic groups. A stabilization of the spectra is observed after $\approx 6 \mathrm{~h}$ of contact with the EDC/NHS solution (see inset of Figure 1B). It has to be noticed that, in the case of EDC 
Scheme 2. EDC and Sulfo-NHS Coupling Scheme ${ }^{a}$<smiles>[R20]NC(=N[R20]O[R9])OC(=O)[R][C](C)C</smiles>

(HA)

(EDC)<smiles>[R20][Y9]=C(N[R20])OC([R])=O</smiles>

(Sulfo NHS)

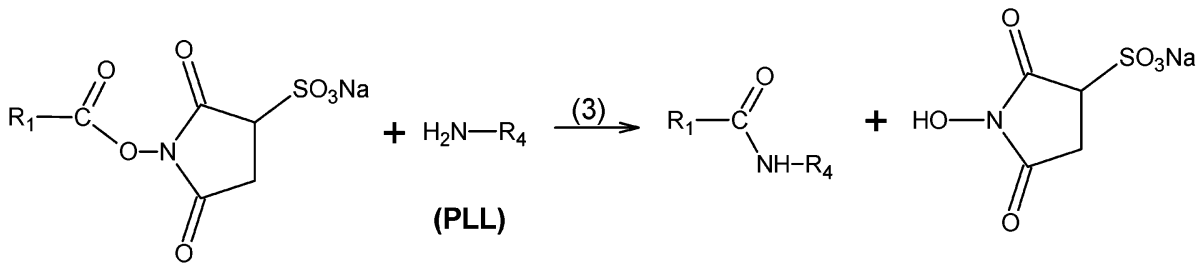

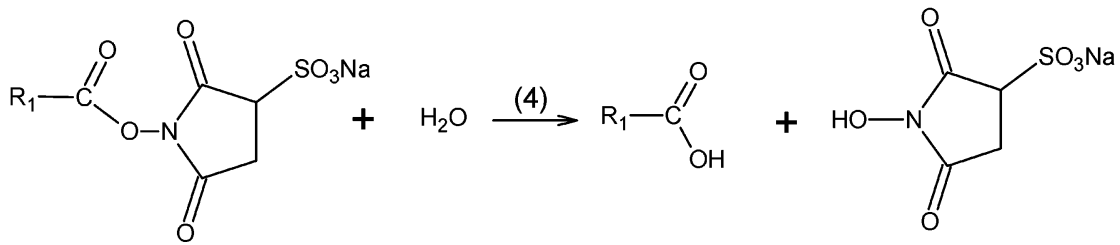

a EDC reacts with a carboxylic group and activates it (1). The activated complex is conversed into an active ester with sulfo-NHS (2). The active ester reacts with primary amine to form an amide bound (3). The unreacted sites are hydrolyzed to give a regeneration of the carboxyls (4).

alone, the FTIR spectrum after contact with the EDC solution for $24 \mathrm{~h}$ showed only very slight changes (data not shown).

Zeta Potential Measurements. The $\zeta$ potential of the film prior to and after the cross-linking is presented in Figure 2. It alternates between +50 and $-50 \mathrm{mV}$ during the film construction for PLL and HA terminating layers respectively, in accordance with former results. ${ }^{14,60}$ Cross-linking was performed both on a negative $(\mathrm{PLL} / \mathrm{HA})_{8}$ and a positive $(\mathrm{PLL} / \mathrm{HA})_{8}-\mathrm{PLL}$ multilayer. Surprisingly, the zeta potential of the cross-linked films, whether negatively or positively ending, is always negative and of the order of $-55 \mathrm{mV}$. Adding a new positive PLL layer on top of the cross-linked films leads to a charge reversal. Subsequent PLL and HA depositions on the cross-linked film lead again to an alternate charge reversal after each deposition step. It thus seems possible to continue the layer-by-layer buildup on top of a cross-linked film. Moreover, the fact that a PLL ending film becomes negatively charged after cross-linking seems to indicate that the outer layer is essentially formed of HA chains. There may also be some unreacted sulfo-NHS molecules on top of the film.

Viscoelastic Changes. We also followed in situ the film buildup and the subsequent cross-linking by QCM-D. As found in a previous study, ${ }^{14}$ the rescaled frequency shifts $-\Delta f / v$ increase exponentially (data not shown) with the number of deposition steps indicating, as a first approxima- tion, that the mass of the film also increases exponentially. It has been shown that this exponential growth is related to the "in" and "out" diffusion of PLL through the whole film during each PLL deposition step. Moreover the values of $-\Delta f / v$ do depend on $v$ for a given number of deposition steps, indicating the viscoelastic nature of the material constituting the multilayer. When such a film is brought in contact with the EDC/NHS solution one observes a slight increase in $-\Delta f / v$ and a pronounced decrease of the dissipation factor $D$ for the four resonance frequencies. These changes are represented in Figure 3. The evolutions take place over roughly $5 \mathrm{~h}$. The decrease of $D$ is characteristic of the stiffening of the film. Similar results were obtained when PLL was the outermost layer of the film (data not shown). For a thick polyelectrolyte films (thicker than the penetration depth of the evanescent field), it is also possible to determine by OWLS the film refractive index considering the film as an infinite medium. ${ }^{44}$ The refractive index noticeably increases as the cross-linking is performed, and it changes from 1.380 before the cross-linking to 1.395 after the cross-linking. This suggests that the film has become more dense.

Changes in the Diffusion Properties of PLL. We used confocal laser scanning microscopy (CLSM) to get information on the (PLL/HA $)_{i}$ film thickness and on the diffusion process through the native and cross-linked films. This 

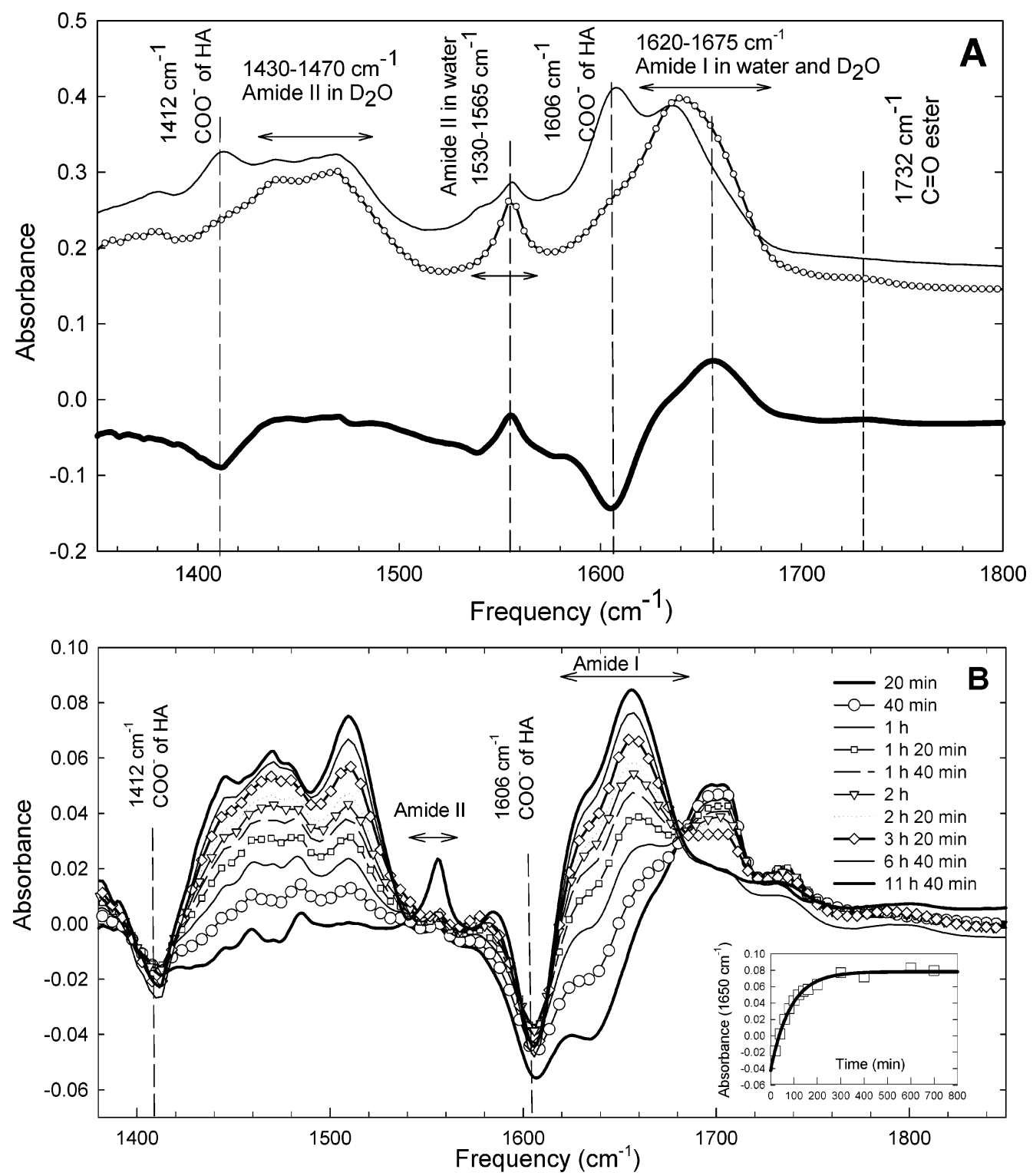

Figure 1. ATR-FTIR spectra of a native and a cross-linked (PLL/HA $)_{8}$ film. (A) before ( - ) and after the cross-linking procedure and the final rinsing step (-O-). Cross-linking was achieved by contact with the EDC/NHS solution for $12 \mathrm{~h}$ at room temperature. The difference between the two spectra (before and after cross-linking) is also represented (thick black line). (B) Evolution of the difference between the actual spectra during the contact with the EDC/NHS solution and the spectrum recorded for the (PLL/HA) $)_{8}$, as a function of the contact time (from 20 min to $12 \mathrm{~h}$; the contribution of the multilayer film was subtracted to the actual spectrum at each contact time). (Inset) The evolution of the absorbance at $1650 \mathrm{~cm}^{-1}$ as a function of time (black square) and the corresponding exponential fit.

technique allowed us previously to prove the existence of the "in" and "out" diffusion process of PLL through the whole film during each PLL deposition step. ${ }^{44}$ It also gives access to the thickness of the films for films typically thicker than $1 \mu \mathrm{m}$. The use of an automatic dipping machine together with the visualization by CLSM allows us to follow the thickness $d$ for films made of a large number $n_{\mathrm{b}}$ of pairs of layers. As can be seen in Figure 4, the behavior of $d$ with $n_{\mathrm{b}}$ is fully compatible with an exponential growth, and one reaches a thickness of the order of $12 \mu \mathrm{m}$ for 30 pairs of layers (native films). As a supplementary experimental proof for the cross-linking of the film, fluorescence recovery after photobleaching (FRAP) experiments were performed by CLSM on un-cross-linked and cross-linked (PLL/HA) 20 PLL-FITC films. A circular zone was bleached, and images were taken immediately after the bleach and after a $30 \mathrm{~min}$ delay (Figure 5, parts A and B). Intensity profiles along the
$X$ axis are plotted for the two images (Figure 5, parts $\mathrm{C}$ and D). For un-cross-linked films (Figure 5, parts A and C), one observes a partial recovery of the fluorescence in the bleached zone, whereas for cross-linked films, no recovery is found (Figure 5, parts B and D). This indicates the absence of PLL-FITC diffusion in the cross-linked films. For non cross-linked films, the diffusion coefficient $D$ of the PLL chains can be estimated to be of the order of $\left\langle\operatorname{dist}^{2}\right\rangle /(2 \times t)$ $=2 \times 10^{-9} \mathrm{~cm}^{2} \mathrm{~s}^{-1}$ where dist corresponds to half the width of the bleached rectangle $(\approx 28 \mu \mathrm{m})$ and $t$ the diffusion time $(t \approx 1800 \mathrm{~s})$. This value is largely smaller than the value of $10^{-7}-10^{-8} \mathrm{~cm}^{2} \mathrm{~s}^{-1}$ estimated from the evolution of optical waveguide light mode spectroscopy data during the deposition steps of PLL as the film is built. ${ }^{14}$ The difference can be explained by the fact that the CLSM experiments were performed $24 \mathrm{~h}$ after the film buildup. During this period of time, "free" PLL-FITC chains present in the film could 

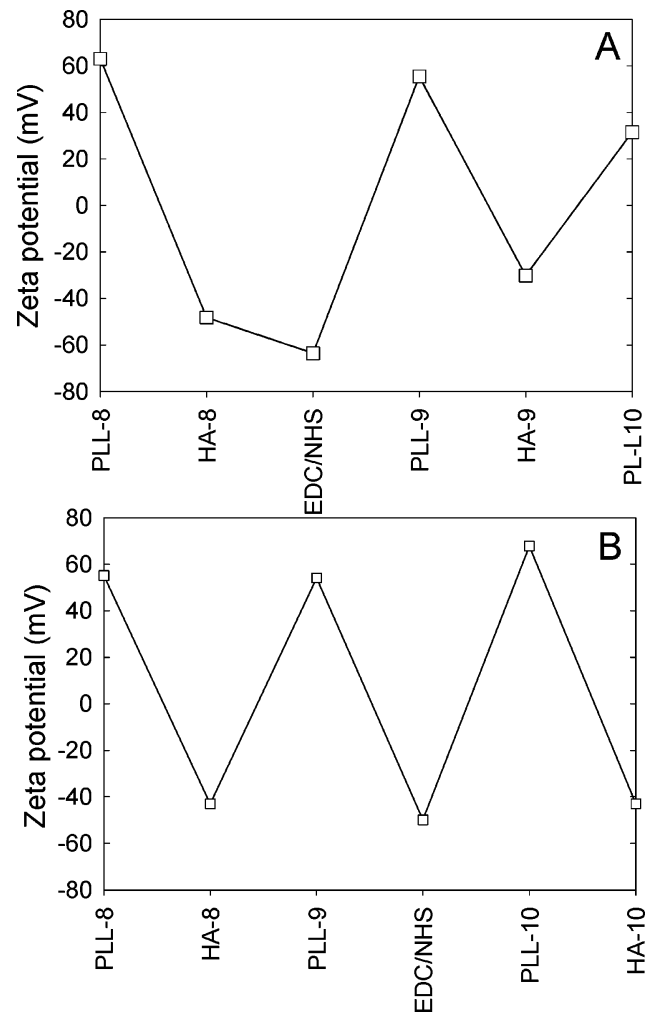

Figure 2. Evolution of the zeta potential $(\mathrm{mV})$ for $(\mathrm{PLL} / \mathrm{HA})$ films prior to and after the cross-linking with EDC/NHS as a function of the layers deposited $(\square)$. PLL (MW $\left.3 \times 10^{4} \mathrm{Da}\right)$ and HA (MW $\left.4 \times 10^{5} \mathrm{Da}\right)$ were prepared at $1 \mathrm{mg} / \mathrm{mL}$ in a $0.15 \mathrm{mM} \mathrm{NaCl}$ solution containing $0.15 \mathrm{M}$ $\mathrm{NaCl}$. Each point represents the mean value of three successive measurements. Standard deviations are so small that they are not visible on the graph. Additional PLL and HA layers have been adsorbed on the cross-linked films. (A) Cross-linking of a negatively ending $(\mathrm{PLL} / \mathrm{HA})_{8}$ film. (B) Cross-linking of a positively ending $(\mathrm{PLL} / \mathrm{HA})_{8}-\mathrm{PLL}$ film. For clarity, the values of the zeta potential for the previous layers (from first until 8 pairs of layers) are not represented.

exchange with PLL chains from the PLL/HA network and could gradually establish links with this network, reducing greatly their mobility. The existence of such an exchange process has been proven in a previous study. ${ }^{44}$ The fact that the PLL diffusion within the film is greatly reduced after cross-linking is a supplementary indication for the successful involvement of PLL in the coupling reaction with HA.

Further evidence that cross-linking changes the internal structure of the film comes from the deposition of PLL-FITC onto a previously cross-linked but non labeled (PLL/HA) $)_{20}$ film. Whereas a (PLL/HA) $)_{20}-$ PLL-FITC film (which has been cross-linked after the deposition of PLL-FITC) appears uniformly green (Figure 6A), there is no visible fluorescence on a cross-linked (PLL/HA) ${ }_{20}$ film on top of which a PLLFITC layer has been adsorbed using the same adjustment for the detector gain of the CLSM apparatus (Figure 6B). By increasing the detector gain by a factor of 2 , a very thin green line becomes visible (Figure 6C), but the noise is also greatly increased, as can be seen by the large number of green pixels over all of the image (and not especially within the film). This thin line, located on the top of the film, has a thickness of the order of $1 \mu \mathrm{m}$ which is much smaller than the $\approx 5 \mu \mathrm{m}$ thickness of the (PLL/HA) $)_{20}-$ PLL-FITC film. This strongly suggests that PLL is no more able to diffuse

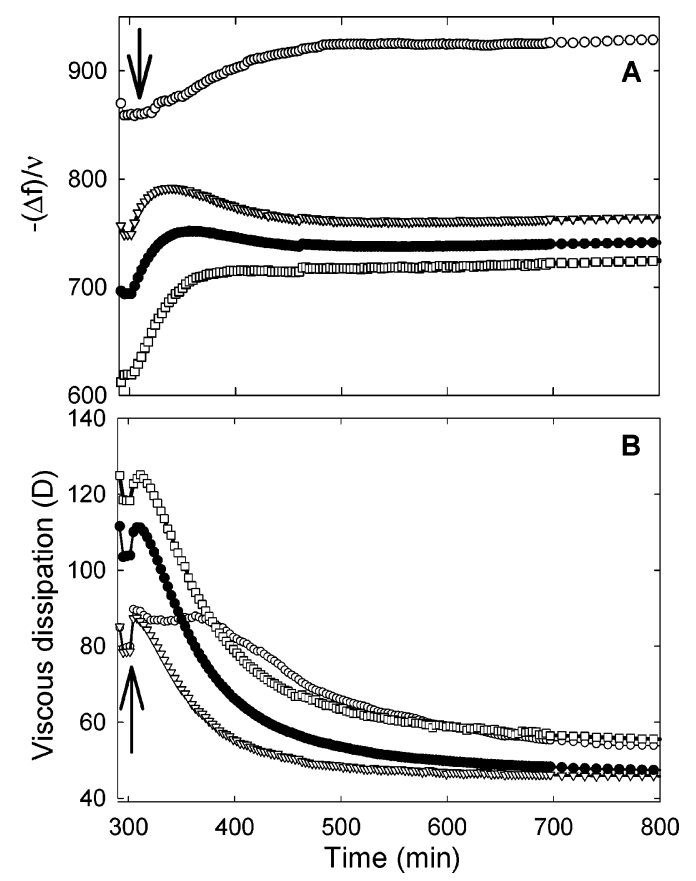

Figure 3. In situ cross-linking of a $(\mathrm{PLL} / \mathrm{HA})_{7}$ film as followed by QCM. (A) Evolution of the frequency shifts $(-\Delta f / v)$ and (B) of the viscous dissipation $D$ as a function of time, after the (PLL/HA $)_{7}$ film has been put in contact with the EDC/sulfo-NHS solution. The four harmonics are represented $(\bigcirc) 5,(\nabla) 15,(\bullet) 25$, and $(\square)$ $35 \mathrm{MHz}$. The arrows indicate the injection of the EDC/sulfo-NHS solution.

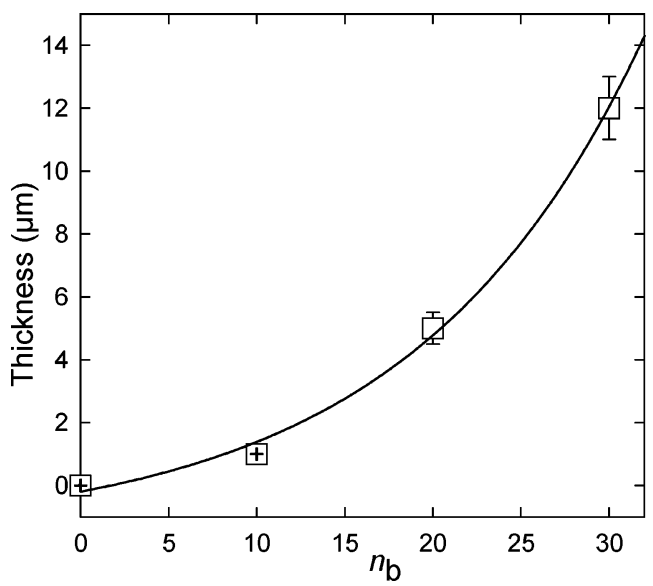

Figure 4. Thickness $d$ of the (PLL/HA) films as a function of the number of pairs of layers $n_{\mathrm{b}}$, as measured by AFM $(+)$ and by CSLM $(\square)$ for films built with the automatic dipping machine on $12 \mathrm{~mm}$ glass slides. AFM height measurements were performed by scratching the film (data taken from ref 14), whereas CLSM measurements were performed using PLL-FITC as the last layer to label the whole film (observation of a green band). Error bars represent the uncertainty on the CLSM measurements.

into a cross-linked film. In the case of EDC alone, when we deposited a PLL-FITC layer on top of a film that had been in contact with EDC, the entire film appeared green suggesting that PLL is still able to diffuse within these films and, thus, that the cross-linking between PLL and HA in the presence of EDC alone is not as efficient as in the presence of EDC/NHS.

This result seems to indicate that PLL-FITC does not diffuse within the cross-linked film during the PLL-FITC deposition step. It could also be due to the absence of exchange process between "free" PLL-FITC chains in the 

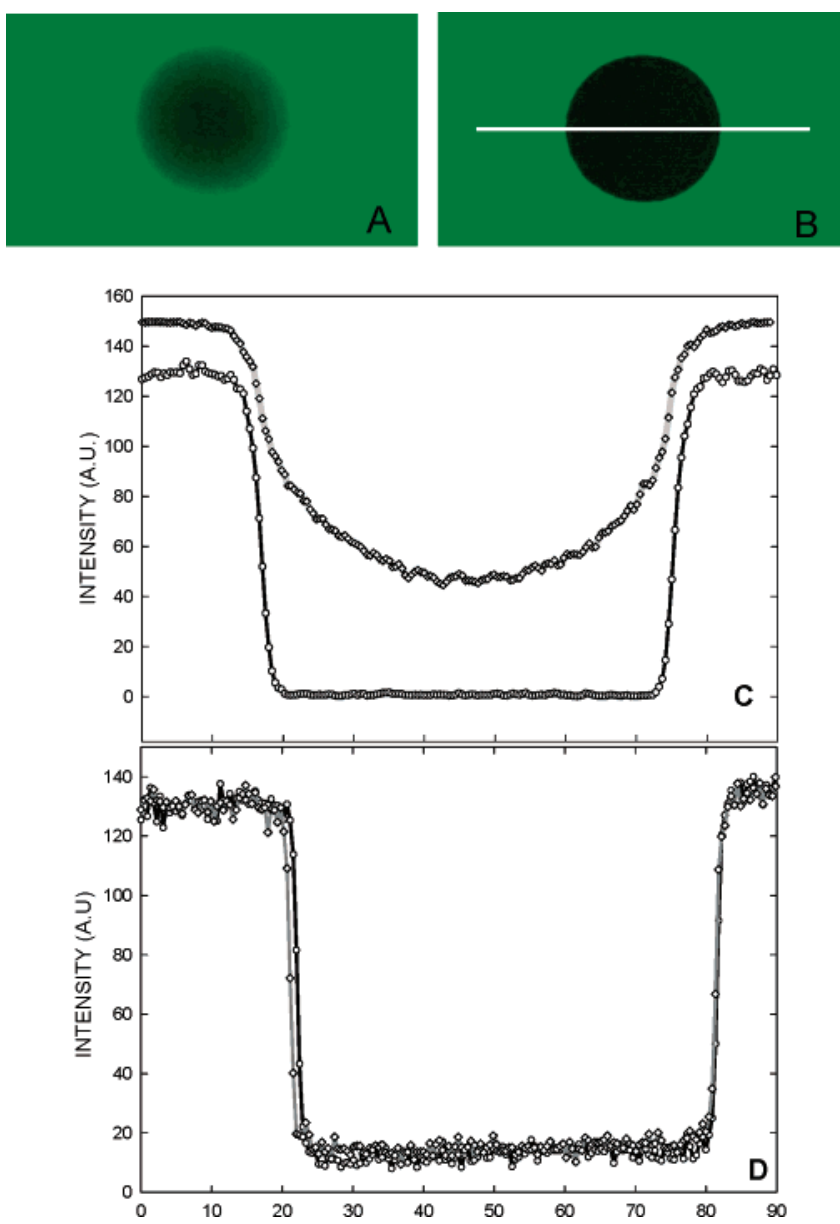

Figure 5. CLSM images taken 30 min after the bleach of the circular zone (around $55 \mu \mathrm{m}$ in diameter). The green fluorescence comes from the (PLL/HA) $20-$ PLL-FITC film. (A) Native film; (B) cross-linked film. The corresponding intensity profiles along the white line from images obtained immediately after the bleach $(O)$ and 30 min after the bleach $(\diamond)$ are given for the (C) native and (D) cross-linked films.

film and PLL chains cross-linked to HA and to the total diffusion (out of the film) of the PLL-FITC during the rinsing step by the aqueous solution. OWLS experiments can bring additional useful information since they were shown to evidence the diffusion of PLL within a thick (PLL/HA) multilayer film. ${ }^{44}$ Experiments performed by OWLS on cross-linked films evidence that there is no more signal changes when PLL and HA are adsorbed after the crosslinking procedure has been performed. This suggests that the first hypothesis is to be preferred.

Stability of the Films: Un-Cross-Linked Versus CrossLinked Multilayers. The stability of the non-cross-linked and cross-linked films in contact with water, with different ethanol solutions, and with hyaluronidase was also investigated. This enzyme is able to cleave hyaluronan. ${ }^{61,62}$ The non-cross-linked (PLL/HA) ${ }_{i}$ multilayers (built in $0.15 \mathrm{M}$ $\mathrm{NaCl}$ solution) are stable in the $0.15 \mathrm{M} \mathrm{NaCl}$ solution for several months, as checked by CLSM, and for at least two weeks when in contact with cells and culture medium (in an incubator at $37^{\circ} \mathrm{C}$ ). Longer times have not been tested in this case. On the other hand, observations performed by CLSM indicate that the films tend to lift up from the substrate locally when the multilayer is transferred from the $0.15 \mathrm{M}$

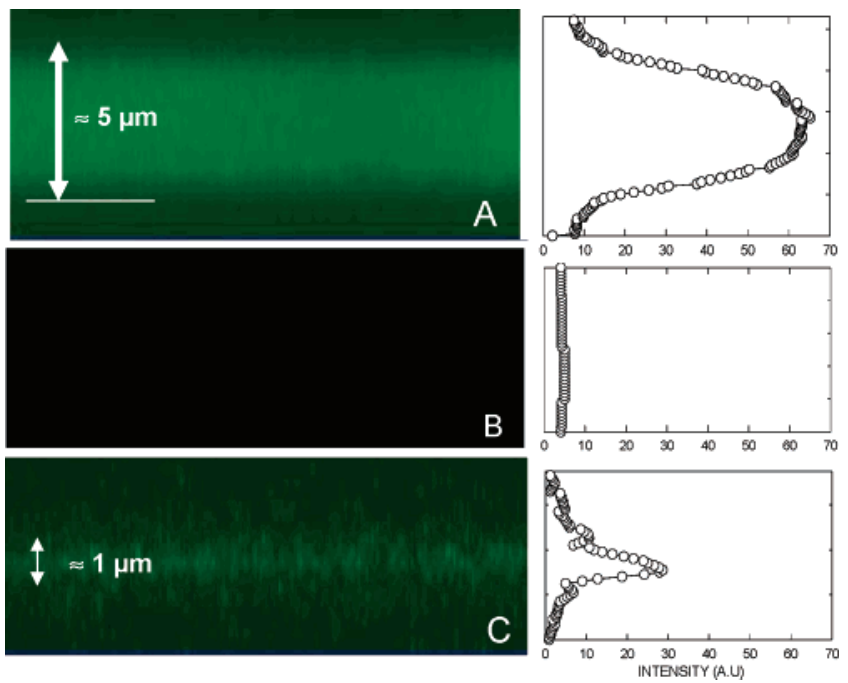

Figure 6. Vertical sections through (PLL/HA) $)_{20}-\mathrm{PLL}-\mathrm{FITC}$ films $(\mathrm{A})$ a cross-linked (PLL/HA) $20-P L L-F I T C$ film for which PLL-FITC has been added before the cross-linking. The thickness of the film is around $5 \mu \mathrm{m}$ as can be seen by the diffusion of the PLL-FITC in the film (white line, image size is $23 \mu \mathrm{m} \times 10 \mu \mathrm{m}$ ). (B) a cross-linked $(\mathrm{PLL} / \mathrm{HA})_{20}$ film on top of which PLL-FITC has been deposited and then rinsed. For this image, the gain and the amplification of the detector were unchanged when compared to (A) (image size is $22.5 \mu \mathrm{m} \times 9.2 \mu \mathrm{m})$. (C) same sample as for image (B) but observed with the detector gain increased by a factor of two. A weak green fluorescence is visible over a short distance at the top of the film (white arrow) because PLL-FITC diffuses weakly into the cross-linked film (image size is $22.5 \mu \mathrm{m} \times 7.2 \mu \mathrm{m}$ ). However, the noise is also greatly increased as can be seen by the large number of green pixels overall the image. On the right side of the images, the corresponding intensity profiles along a section are also given for more clarity.

$\mathrm{NaCl}$ solution into pure water (data not shown). This may be due to strong restructuration effects inside the film or to a weakening of the interactions between the film and the substrate during the transfer of the multilayer into water. On the other hand, the cross-linked (PLL/HA) 20 -PLL-FITC films, are very stable when transferred in water or in water/ ethanol solutions whatever the ethanol proportion is. The thickness of the film as a function of the ethanol concentration is given in Figure 7. The thickness of the cross-linked film continuously decreases as the ethanol content is increased and reaches in pure ethanol a thickness which represents $50 \%$ from its initial value in water. The rehydration of the film is almost fully reversible at the 15 min time period applied here. Such a film thickness decrease as the ethanol content increases may be due to a decrease of the ionic content of the film which would lead to a decrease of the osmotic pressure. Finally, after contact for $42 \mathrm{~h}$ at $37^{\circ} \mathrm{C}$ with a hyaluronidase solution at $1000 \mathrm{U} / \mathrm{mL}$, the topography of a cross-linked film remained unchanged whereas un-crosslinked films were strongly degraded as can be seen in Figure 8. One also observes that the degradation of un-cross-linked films by hyaluronidase leads to a very porous, spongelike film.

Cell Adhesion Properties. The un-cross-linked and crosslinked films were also tested with respect to the adhesion of chondrosarcoma cells, taking bare glass as a reference. These cells were grown on negative (PLL/HA) 12 and positive (PLL/ HA) ${ }_{12}$-PLL films, either native or cross-linked (four conditions). Three slides were used for each condition. On the 


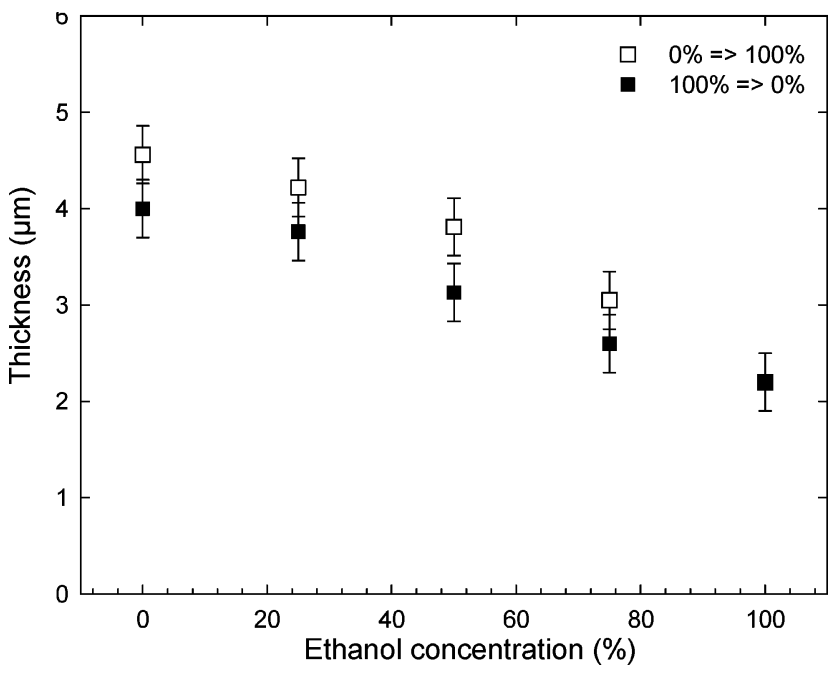

Figure 7. Thickness of a cross-linked (PLL/HA) $)_{20}-\mathrm{PLL}-\mathrm{FITC}$ film as a function of the ethanol concentration as measured by CLSM. Films built and cross-linked in the $0.15 \mathrm{M} \mathrm{NaCl}$ solution were then put in contact with water followed by solutions at increasing ethanol concentrations $(25 \%, 50 \%, 75 \%$, and $100 \%)(\square)$. The rehydration of the films was followed by decreasing ethanol concentration (from pure ethanol to pure water) ( $\square$ ).
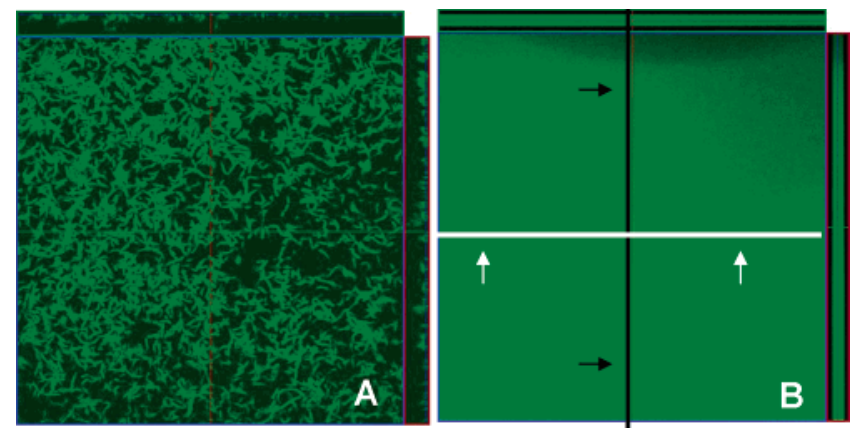

Figure 8. CLSM study of the degradation of a $(\mathrm{PLL} / \mathrm{HA})_{24}-\mathrm{PLL}-\mathrm{FITC}$ film that has been in contact with hyaluronidase (type I, 1000U) for $42 \mathrm{H}$ at $37^{\circ} \mathrm{C}$. (A) native and (B) cross-linked film. Z sections collected at $0.4 \mu \mathrm{m}$ interval were taken with the $40 \times$ oil objective $(230 \mu \mathrm{m} \times$ $230 \mu \mathrm{m}$ ) in order to image the whole films. The top views of the film are shown. Vertical section along the white line (see white arrows and top view) and along the black line (see black arrows and side view) are also represented. The vertical section scales are respectively $12.9 \mu \mathrm{m}$ for the left image and $11.8 \mu \mathrm{m}$ for the right image. From the right image, the cross-linked film thickness can be estimated to be $5.7 \mu \mathrm{m}$.

$(\mathrm{PLL} / \mathrm{HA})_{12}$ and (PLL/HA) $)_{12}$-PLL films, cells neither adhere nor spread at all after 2-6 days of culture (respectively Figure 9, parts A and C). These results hold for both HA and PLL ending films. An important question arises as to whether any cells ever did initially adhere to and then subsequently detached from the polyelectrolyte films. Such behavior would suggest that the multilayers are potentially cytotoxic. However, this nonadhesion is not due to a toxicity of the films since the cells could adhere at the bottom of the well (on the plastic near the coated glass). Also, if the suspended cells from the un-cross-linked PLL/HA films were transplanted to fresh culture plates, even after 2 days of floating, many cells readily attached and spread similarly to healthy cells. By contrast, cells deposited on the cross-linked HA and PLL ending films adhered and spread well comparably to cells on uncoated glass slides. The surface of the

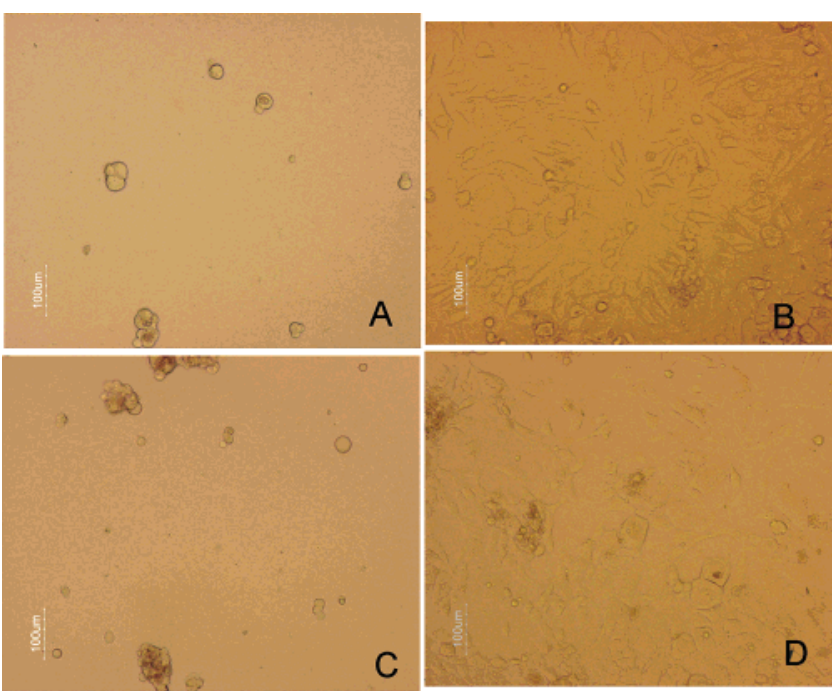

Figure 9. Chondrosarcoma cells (HCS2/8) cultured on native or cross-linked (PLL/HA) 12 and PLL/HA) ${ }_{12}-$ PLL films for 6 days, i.e., films terminating either by $\sim \mathrm{PLL}$ or $\sim \mathrm{HA}:(\mathrm{A}) \sim \mathrm{HA}(\mathrm{B})$ cross-linked $\sim \mathrm{HA}(\mathrm{C}) \sim \mathrm{PLL}$ (D) cross-linked $\sim \mathrm{PLL}$.

cross-linked film was almost entirely covered over the 6 days period of culture (Figure 9, parts B and D). It has to be noticed that these results were obtained only in the case of the EDC/NHS cross-linking protocol and not when EDC alone was used. In this latter case, the films were still highly cell resistant. These findings further demonstrate that there is no effective cross-linking in the absence of sulfo-NHS.

The change from a nonadhesive to an adhesive character of the (PLL/HA) ${ }_{i}$ films after cross-linking may originate from changes in the film rigidity as evidenced by QCM-D and from the strongly reduced diffusion of PLL. Several studies have demonstrated the influence of the rigidity of a substrate on the cell adhesion and movement. Lo et al. ${ }^{37}$ showed, by using polyacrylamide gels coated with collagen, that cell movements can be controlled by purely physical interactions at the cell substrate interface. The rigidity of the gel was adjusted by changing the concentration of the bis-acrylamide cross-linker. These authors evidenced that cells preferred the stiff substrate (what they called the "durotaxis"). This kind of physical rule was further evidenced for neuronal cells. ${ }^{63}$ Moreover, it is expected that cross-linking reduces the hydration of the films and their deswelling and swelling ability consecutive to drying and rehydration. Following Mendelsohn et al, ${ }^{19}$ this should favor cellular adhesion on the films. The issue of protein adhesiveness if often simultaneously investigated when performing in vitro cell studies with biomaterials. However, recent studies on polyelectrolyte multilayers films suggest that differences in protein adhesiveness cannot account for the significant differences in cell-multilayer interactions. ${ }^{19,64}$

Another way to modify film stiffness may be to introduce organic nanocolloids. ${ }^{65,66}$ Titania nanoshells introduced in a layer by layer assembly of poly(diallyldimethylammonium chlroride) (PDDA)/ poly(acrylic acid) (PAA) were found to favor PC12 (a cell lineage) cell attachment onto the films, whereas there was no attachment of the cells to PDDA/PAA multilayers free of particles. The main advantage of the simple cross-linking protocol based on a zero length cross- 
linker such as EDC is that it does not introduce additional molecule or particle that may be toxic in in vivo applications. Future work is also needed in vitro to investigate the properties of native and cross-linked films with respect to primary cells which are much more sensitive than cell lineages.

\section{Conclusion}

We successfully demonstrated that polyelectrolyte multilayered films containing carboxylic and ammonium groups can be chemically cross-linked by means of a water soluble carbodiimide EDC in combination with sulfo NHS. We also proved that the use of sulfo-NHS in combination with EDC was necessary for getting an effective cross-linking of the films. Fourier transform infrared spectroscopy evidences the conversion of these groups into amide bonds. The zeta potential of the films becomes negative after the crosslinking. As a first consequence of the cross-linking, the rigidity and the density of the film are increased, as suggested by the decrease in the viscous dissipation observed by QCM and the increase in the film refractive index measured by OWLS. As a second consequence of the cross-linking, CLSM images demonstrate that the diffusion of the PLL-FITC within the (PLL/HA $)_{i}$ films has vanished and the cross linking hinders further diffusion of PLL chains within the film when it is brought in contact with a PLL solution. Moreover cross-linked films adhere in a much more stable way than non-cross-linked ones to the substrate. Finally, cross-linked films are stable in ethanol and they are not degraded by hyaluronidase (over a $42 \mathrm{~h}$ incubation period at $37^{\circ} \mathrm{C}$ ), whereas the non-cross-linked films are highly degraded when exposed to this enzyme. As a consequence of the cross-linking, chondrosarcoma cells do adhere very well on the films terminating either with PLL or HA whereas the native films are highly cell anti-adhesive. This effect is explained by an increase of the film rigidity after cross linking.

Acknowledgment. We thank Prof. D. E. Discher (University of Pennsylvania, Philadelphia), Dr. R. Richter (QSense), Prof. G. D. Prestwich (University of Utah, Salt Lake City), and Dr. B. Frisch (CNRS, Strasbourg) for fruitful discussions. We also thank G. Marzoff and G. Bonani for their technical help. This work was supported by the programs ACI "Technologies pour la Santé" and ACI "Surfaces, interfaces et conception de nouveaux matériaux" from the Ministère Français de la Recherche. The CLSM platform used in this study was co-financed by the Région Alsace, the CNRS, the Université Louis Pasteur, and the Association pour la Recherche sur le Cancer.

\section{References and Notes}

(1) Castner, D. G.; Ratner, B. D. Surf. Sci. 2002, 500, 28-60.

(2) Healy, K. E. Curr. Opin. Solid State Mater. Sci. 1999, 4, 381-387.

(3) Ratner, B. D.; Hoffman, A. S.; Schoen, F. J.; Lemons, J. E. Biomaterials sicence: an introduction to materials in medecine; Academic Press: New York, 1996.

(4) Decher, G.; Hong, J. D.; Schmitt, J. Thin Solid Films 1992, 831835 .

(5) Decher, G. Science 1997, 277, 1232-1237.
(6) Bertrand, P.; Jonas, A.; Laschewsky, A.; Legras, R. Macromol. Rapid. Commun. 2000, 21, 319-348.

(7) Schönhoff, M. Curr. Opin. Colloid Interface Sci 2003, 8, 86-95.

(8) Shiratori, S. S.; Rubner, M. F. Macromolecules 2000, 33, 42134219.

(9) Dubas, S. T.; Schlenoff, J. B. Macromolecules 2001, 34, 3736.

(10) Fery, A.; Schöler, B.; Cassagneau, T.; Caruso, F. Langmuir 2001, 17, 3779-3783.

(11) Elbert, D. L.; Herbert, C. B.; Hubbell, J. A. Langmuir 1999, 15, $5355-5362$.

(12) Serizawa, T.; Yamaguchi, M.; Akashi, M. Biomacromolecules 2002, 3, 724-731.

(13) Shenoy, D. B.; Antipov, A.; Sukhorukov, G. B.; Möhwald, H. Biomacromolecules 2003, 4, 265-272.

(14) Picart, C.; Lavalle, P.; Hubert, P.; Cuisinier, F. J. G.; Decher, G.; Schaaf, P.; Voegel, J. C. Langmuir 2001, 17, 7414-7424.

(15) Chluba, J.; Voegel, J. C.; Decher, G.; Erbacher, P.; Schaaf, P.; Ogier, J. Biomacromolecules 2001, 2, 800-805.

(16) Jessel, N.; Atalar, F.; Lavalle, P.; Mutterer, J.; Decher, G.; Schaaf, P.; Voegel, J. C.; Ogier, G. Adv. Mater. 2003, 15, 692-695.

(17) Boura, C.; Menu, P.; Payan, E.; Picart, C.; Voegel, J. C.; Muller, S.; Stoltz, J.-F. Biomaterials 2003, 24, 3521-3530.

(18) Tryoen-Toth, P.; Vautier, D.; Haikel, Y.; Voegel, J.-C.; Schaaf, P.; Chluba, J.; Ogier, J. J. Biomed. Mater. Res. 2002, 60, 657-667.

(19) Mendelsohn, J. D.; Yang, S. Y.; Hiller, J.; Hochbaum, A. I.; Rubner, M. F. Biomacromolecules 2003, 4, 96-106.

(20) Eckle, M.; Decher, G. Nano Lett. 2001, 1 (1), 45-49.

(21) Kovacevic, D.; van der Burgh, S.; de Keizer, A.; Cohen Stuart, M. A. Langmuir 2002, 18, 5607-5612.

(22) Brynda, E.; Houska, M. J. Colloid Interface Sci. 1996, 183, 18-25.

(23) Leporatti, S.; Voigt, A.; Mitlöhner, R.; Sukhorukov, G.; Donath, E.; Möhwald, H. Langmuir 2000, 16, 4059-4063.

(24) Chen, J.; Huang, L.; Ying, L.; Luo, G.; Zhao, X.; Cao, W. Langmuir 1999, 15, 7208-7212.

(25) Vuillaume, P. Y.; Jonas, A. M.; André Laschewsky, A. Macromolecules 2002, 35, 5004-5012.

(26) Tengvall, P.; Jansson, E.; Askendal, A.; Thomsen, P.; Gretzer, C. Colloids Surf. B. 2003, 28, 261-272.

(27) Harris, J. J.; DeRose, P.; Bruening, M. J. Am. Chem. Soc. 1999, 121, 1978.

(28) Dai, J.; Jensen, A.; Mohanty, D.; Erndt, J.; Bruening, M. Langmuir 2001, 17, 931-937.

(29) Lee, B. J.; Kunitake, T. Langmuir 1994, 10, 557-562.

(30) Anagi, M.; Balachandra, A. M.; Dai, J.; Bruening, M. L. Macromolecules 2002, 35, 3171-3178.

(31) Timkovich, R. Anal.Biochem. 1977, 79, 135-143.

(32) Grabarek, Z.; Gergely, J. Anal. Biochem. 1990, 185, 131-135.

(33) Tomihata, K.; Ikada, Y. J. Biomed. Mater. Res. 1997, 37, 243-251.

(34) Park, S.-N.; Park, J.-C.; Kim, H. O.; Song, M. J.; Suh, H. Biomaterials 2002, 23, 1205-1212.

(35) Taguchi, T.; Ikoma, T.; Tanaka, J. J. Biomed. Mater. Res. 2002, 61, $330-336$.

(36) Pelham, R. J., Jr.; Wang, Y. 1. Proc. Natl. Acad. Sci. 1997, 94, 13661-13665.

(37) Lo, C. M.; Wang, H. B.; Dembo, M.; Wang, Y. L. Biophys. J. 2000, $79,144-152$.

(38) Hermanson, G. T. In Bioconjugate techniques; Hermanson, G. T., Ed.; Academic Press: San Diego, 1996; pp 169-176.

(39) Schwinté, P.; Voegel, J.-C.; Picart, C.; Haikel, Y.; Schaaf, P.; Szalontai, B. J. Phys. Chem. B 2001, 105, 11906-11916.

(40) Tiefenthaler, K.; Lukosz, W. J. Opt. Soc. Am. B 1989, 6, 209-220.

(41) Picart, C.; Ladam, G.; Senger, B.; Voegel, J.-C.; Schaaf, P.; Cuisinier, F. J. G.; Gergely, C. J. Chem. Phys. 2001, 115, 1086-1094.

(42) Rodahl, M.; Kasemo, B. Sens. Actuators B (Chem.) 1996, B37, 111116.

(43) Hook, F.; Rodahl, M.; Brzezinski, P.; Kasemo, B. J. Colloid Interface Sci. 1998, 208, 63-67.

(44) Picart, C.; Mutterer, J.; Richert, L.; Luo, Y.; Prestwich, G. D.; Schaaf, P.; Voegel, J.-C.; Lavalle, P. Proc. Natl. Acad. Sci. 2002, 99, 1253112535.

(45) Zembala, M.; Déjardin, P. Colloids Surf. B 1994, 3, 119-129.

(46) Ladam, G.; Schaad, P.; Voegel, J. C.; Schaaf, P.; Decher, G.; Cuisinier, F. Langmuir 2000, 16, 1249-1255.

(47) Tagikawa, M.; Tajama, K.; Pan, H. O.; Enmoto, M.; Kinoshita, A. Suzuki, F.; Takano, Y.; Mori, Y. Cancer Res. 1989, 49, 3996-4002.

(48) Laurent, T. C. The chemistry, biology, and medical applications of hyaluronan and its derivatives; Cambridge University Press: Cambridge, U.K., 1998; Vol. 72

(49) Danishefsky, I.; Siskovic, E. Carbohydr. Res. 1971, 16, 199-205. 
(50) Ogamo, A.; Matsuzaki, K.; Uchiyama, H.; Nagasawa, K. Carbohydr. Res. 1982, 105, 69-85.

(51) Kuo, J. W.; Swann, D. A.; Prestwich, G. D. Bioconjugate Chem. 1991, 2, 232-241.

(52) Kurzer, F.; Douraghi-Zedeh, K. Chem. Rev. 1967, 67, 107-152.

(53) Bulpitt, P.; Aeschlimann, D. J. Biomed. Mater. Res. 1999, 47, 152169.

(54) Pouyani, T.; Kuo, J. W.; Harbison, G. S.; Prestwich, G. D. J. Am. Chem. Soc. 1992, 15

(55) Araki, J.; Wada, M.; Kuga, S. Langmuir 2001, 17, 21-27.

(56) Haxaire, K.; Marechal, Y.; Milas, M.; Rinaudo, M. Biopolymers 2003 , $72,10-20$.

(57) Boulmedais, F.; Ball, V.; Schwinte, P.; Frisch, B.; Schaaf, P.; Voegel, J. C. Langmuir 2002, 19, 440-445.

(58) Zuber, G.; Prestrelski, S. J.; Benedek, K. Anal. Biochem. 1992, 207, $150-156$.

(59) Haxaire, K.; Marechal, Y.; Milas, M.; Rinaudo, M. Biopolymers 2003, $72,149-161$
(60) Rickert, J.; Brecht, A.; Gopel, W. Biosens. Bioelectron. 1997, 12, 567-575.

(61) Alberts, B.; Bray, D.; Lewis, J.; Raff, M.; Roberts, K.; Watson, J. D. Molecular biology of the cell; Garland Publishing Inc: New York, 1994.

(62) Prestwich, G. D.; Marecak, D. M.; Marecek, J. F.; Vercruysse, K. P.; Ziebell, M. R. J. Controlled Release 1998, 53, 93-103.

(63) Flanagan, L. A.; Ju, Y. E.; Marg, B.; Osterfield, M.; Janmey, P. A. Neuroreport 2002, 13, 2411-2415.

(64) Richert, L.; Lavalle, P.; Vautier, D.; Senger, B.; Stoltz, J.-F.; Schaaf, P.; Voegel, J.-C.; Picart, C. Biomacromolecules 2002, 3, 1170-1176.

(65) Tang, Z.; Kotov, N. A.; Magonov, S.; Ozturk, B. Nat. Mater. 2003 , 2, 413-418.

(66) Koktysh, D. S.; Liang, X.; Yun, B. G.; Pastoriza-Santos, I.; Matts, R. L.; Giersig, M.; Serra-Rodríguez, C.; Liz-Marzán, L. M.; Kotov, N. A. Adv. Funct. Mater. 2002, 12, 255-265.

BM0342281 